\title{
Characterization of Lifetime Agrichemical Exposure Sequences Relative to International Migration in Foreign Born Latinx Agricultural Workers Living in South Florida
}

\author{
Mike Anastario $^{1}$ (D ) Ana Maria Rodriguez ${ }^{1} \cdot$ Nezahualcoyotl Xiuhtecutli $^{2} \cdot$ Eric Wagner $^{1}$ \\ Accepted: 16 September 2021 / Published online: 24 September 2021 \\ (c) The Author(s), under exclusive licence to Springer Science+Business Media, LLC, part of Springer Nature 2021
}

\begin{abstract}
There is a limited understanding of how toxic exposures to agrichemicals vary relative to international migration over the life course. A life history calendar (LHC) was piloted to explore sequences of agrichemical exposure relative to international migration. LHCs were administered to 41 foreign born individuals from Mexico and Central America who had agricultural work experience during their lifetime and who were living in South Florida. Social sequence analysis was used to explore occupation-by-agrichemical events relative to migration. A three-cluster solution was used to classify low, moderate, and high lifetime exposure sequences. The odds of any perceived effects of agrichemicals on the body increased with time prior to migration in the moderate and high exposure sequence clusters and continued to increase $20 \%$ with each year following migration in the moderate exposure cluster. Workers with high lifetime agrichemical exposures prior to migrating internationally showed lower likelihoods of a perceived effect on the body following migration despite continued exposure. Further research on instrument validity is warranted.
\end{abstract}

Keywords Life history calendar $\cdot$ Agricultural workers $\cdot$ Immigrants $\cdot$ Agrichemicals $\cdot$ Social sequence analysis

\section{Introduction}

The agricultural sector is considered to be one of the most hazardous sectors of work, and employs more than a third of the world's labor force $[1,2]$. In addition to injuries and heat exposure, toxic agrichemical exposures are a serious concern [3]. An estimated $44 \%$ of farmers worldwide experience unintentional, acute pesticide poisoning annually [4]. Migrant farmworkers in the United States (US) experience high pesticide exposure in work environments and the home [5], and Latinx farmworkers have been found to report higher levels of lifetime and residential pesticide exposure in comparison to non-farmworking Latinxs [6]. There is currently a limited understanding of how toxic exposures to agrichemicals vary relative to international migration

Mike Anastario

manastar@fiu.edu

1 Robert Stempel College of Public Health \& Social Work, Florida International University, ACH5 11200 SW 8th St, Miami, FL 33174, USA

2 Farmworker Association of Florida, Apopka, FL, USA experiences for foreign-born farmworkers who are currently in the US. This gap in the literature is important to address given the unique health risks that may be faced by foreignborn farmworkers.

A wide range of health effects including cancer, reproductive health problems, and disruption of endocrine, immune, and central nervous systems have been associated with pesticide exposure [7]. Reliance on self-reported exposures is one way of approximating chronic exposure given that many pesticides used in agricultural labor are nonpersistent and metabolized in the human body in a matter of days [2]. This is complicated by agricultural workers in the US often having low knowledge of their pesticide exposures [2], with one focus group study finding that workers relied on their senses to detect the presence of pesticides [8].

In contrast to agricultural labor in the US, small-scale subsistence farmers in Central America may have more control over the decisions made, technologies used, and temporal rhythms associated with cultivation practices on farms [9]. For foreign-born agricultural workers currently living and working in the US, earlier parts of the individual's life may be spent in subsistence farming lifeways prior to migrating to the US and subsequent entry into 
agricultural wage labor. The drastic differences in work environments between countries may entail differential experiences with agrichemicals over the life course within the same migrant.

From a life course perspective, experiences of subsistence farming and agrichemical exposure in a migrant's country of origin may vary relative to the age of the foreign-born agricultural worker. The "Green Revolution" of the 1960s and 1970s (the deployment of modern agricultural technology to developing countries) resulted in a late twentieth century shift away from fire and fallow methods, and increased reliance on synthetic fertilizers, herbicides, and pesticides throughout Mexico and Central America $[10,11]$. Subsistence farming methods including cultivating a "milpa," which is derived from the word for "field" in Nahuatl and is today used to refer to an individual corn farm that may be intercropped with legumes, squash, and other plants, and where swidden (fire and fallow) cultivation techniques are used in conjunction with an increasing number of agrichemicals in parts of Mexico and Central America [9, 12-14]. This shift in agrichemical use is reflected in the increased imports of pesticides in the 1990s that correlated with increased deaths due to pesticide poisoning in the region [15]. Thus, pre-international migration experiences with rapidly shifting subsistence farming environments in Central America and Mexico are important to understand when considering questions of chronic toxicity and agrichemical exposures in foreignborn agricultural workers in the US. Furthermore, it is important to delineate the occupational histories of agricultural workers migrating from regions where there is an emerging epidemic of chronic kidney disease of unknown origin (CKDu) or Mesoamerican nephropathy [16-27], as work experiences in Mexico or Central America prior to coming to the US may differentiate foreign-born Latinx agricultural workers' risks for diseases of the genitourinary system.

In this study, we piloted a life history calendar (LHC) with Latinx agricultural workers born in Central America or Mexico who were currently living in South Florida at the time of the study. The aim of the study was to characterize lifetime agrichemical exposure sequences among foreign born Latinx agricultural workers using social sequence analysis. Social sequence analysis is an analytic technique that can be used to understand sequential phenomena, elucidating affinity typologies between actors who do not necessarily have physical interaction, but shared experiences that emerge through synchronous acts $[28,29]$. Findings will have implications for developing methods to improve an understanding of how toxic exposures to agrichemicals throughout the life course affect risk factors for disease in foreign born Latinx agricultural workers.

\section{Methods}

\section{Setting and Study Design}

The objective of the study was to pilot a Spanish-language LHC with foreign-born Latinx agricultural workers in South Florida. Researchers from Florida International University (FIU) worked with the Farmworker Association of Florida (FWAF), a non-profit grassroots farmworker membership organization, to design the research protocol, collect and interpret data. The study took place in Immokalee, Florida, a predominantly Hispanic (72.1\%) community located in Collier County, Florida [30]. All data collection procedures described below occurred in Spanish. Data collection took place from March through May 2021. The FIU team was vaccinated for COVID-19 prior to data collection, and safety protocols including the distribution of personal protective equipment to data collectors and participants were used to reduce the risk of transmission during data collection.

Eligible participants were Latinx individuals born in Mexico or Central America who had any agricultural work experience during their life course. Participants were recruited using a purposive snowball sampling strategy through monthly FWAF meetings and FWAF member networks. Interviews were conducted in a private room with printed, poster sized LHCs spread out on a table. Interview incentives included $\$ 40$ for participation. Ethical approval for the study was given the by the FIU Institutional Review Board. In total, 42 participants ( 27 female, 15 male) completed interviews, but one participant was excluded when the LHC activity revealed that the participant was born in the US. The gender imbalance in the sample emerged early on during sampling, and an effort was made throughout the remainder of the study to recruit more men, resulting in the final sample. Ages of participants ranged from 18 to 70 . All participants provided verbal informed consent prior to being interviewed, which was chosen as the primary mode of consent given that both illiteracy and undocumented status were characteristics of some participants.

\section{Life History Calendar (LHC)}

The LHC is a timeline-based instrument that can be used to collect data regarding past occupational experiences and self-reported exposures relative to a given time period [31], which in this case was the entire life course. LHCs may help participants remember aspects of their past by anchoring events to other life events, and can be a particularly useful interviewing technique for individuals with low literacy levels and complex employment histories 
[32-41]. The LHC used in this study appeared on two $30^{\prime \prime} \times 42^{\prime \prime}$ poster sized sheets of paper, and included up to 70 columns/years per item (one LHC was collected electronically to evaluate the feasibility of that modality). On average, LHCs took 66 min to complete (range 38-105). Erasable colored pencils were used to record participants' experiences such that participants who could not read would be able to anchor their responses to a color representation of a given experience on the LHC. Participants were encouraged to provide their feedback/corrections as their responses were entered.

\section{Measures}

\section{Occupation-by-Agrichemical Exposure Sequences Relative to International Migration}

Participants were first asked to delineate their international migration experiences, followed by their occupational experiences over the life course. Responses were plotted horizontally on the LHC using different colors. For each occupation that required agricultural labor, a follow-up inventory of agrichemical use was administered. Participants were asked to recall years of involvement in pesticide mixing, insecticide application, herbicide application, fungicide application, fertilizer application, working in a field where someone else was applying pesticide, application of an unknown chemical, using a backpack pump to apply chemicals, using machinery or other equipment to apply chemicals, and agrichemical storage inside the home. Fertilizer use was measured to help respondents with recall over the life course, particularly in milpa/subsistence farming environments where fertilizers, herbicides, and pesticides are purchased by farmers and applied relative to the corn growth cycle among farmers capable of articulating their names [9]. Responses were plotted using the color code of the occupational activity. Follow-up questions for a positive response included the name(s) of the agrichemical used and whether personal protective equipment (PPE) was used. Individual count variables were developed to represent the total number of pesticides (range 0-8), fertilizers (range 0-3), and combined agrichemicals reported (range 0-9) via LHC.

A nominal variable was developed to represent occupation-by-agrichemical exposure events during the life course, classified as: 1 . Subsistence/milpa farming with agrichemicals; 2. Subsistence/milpa farming without agrichemicals; 3. Agricultural wage labor with agrichemicals; 4. Agricultural wage labor without agrichemicals; 5 . Landscaping with agrichemicals; 6. Landscaping without agrichemicals; 7. Construction; 8. Painting; 9. Other work; and 10. Not working. Year of first migration was added as an $11^{\text {th }}$ category to each participant's sequence. This final variable was used to conduct the social sequence analyses described below.

\section{Self-reported Perceptions of Agrichemical Exposures on the Body}

After completing agrichemical use inventories, participants were asked whether a given chemical affected their body in any way. Participants free-listed effects, which were subsequently coded into five dichotomous variables $(0=$ none reported, $1=$ effect reported) representing irritation to the eyes, skin or fingernails, airways, and/or central nervous system (CNS) (including nausea, vomiting, dizziness, and headache). A summary measure of any effect $(0=$ none, $1=$ any $)$ was developed by combining the prior four.

\section{Data Analysis}

The unbalanced panel data were first explored for cumulative lifetime measures of experience with agrichemicals. Data were balanced by centering the panel data on first year of migration to the US, and only including observations \pm 10 years relative to migration (21 observations total per respondent, $\mathrm{n}=861$ ). For the $7.8 \%$ of participants who reported $<10$ years in the US after migrating, values were imputed up to a 10th year using the observations derived from the last reported year in the US. Probability state transition matrices (PSTMs) were examined to evaluate adjacent probabilities between sequence elements. [28] Optimal matching was conducted using SQ-Ados in Stata $[42,43]$. Sequences were aligned using indels and substitutions, with alignment costs weighed using the Levenshtein distance of 1 for each. A square dissimilarity matrix containing the Levenshtein distances was used to conduct agglomerative hierarchical cluster analysis. Visual inspection of dendograms and the Calinski and Harabasz Index was used to evaluate class membership [28]. Sequence index plots were developed as visual aids in the interpretation of sequence cluster analysis findings.

Finally, sequence clusters were entered as independent variables into random effects models for self-reported perceptions of agrichemical exposures on the body. Random-intercepts for individuals were specified, and adjusted odds ratios (aORs) estimated for sequence cluster by time-relative-to-migration (TRM) interaction effects, with gender and language of participant modeled as fixed effects. To aid interpretation of the interaction effects detected, spline basis functions were generated for years prior to $(-10 \leq \mathrm{t} \leq 0)$ and following $(0<\mathrm{t} \leq 10)$ migration, and piecewise-linear random-coefficient (PLRC) models were conducted separately within each sequence cluster. 


\section{Results}

Twenty-seven participants (66\%) self-identified as female and $14(34 \%)$ as male (Table 1). There were 25 Spanish speakers and 16 bilingual Spanish/Indigenous language speakers (Mam, Nahuatl, Zapotec, Mixteco, Otomi, and Chinanteco). Most participants were from Mexico $(n=27)$ followed by Guatemala $(n=13)$ and Honduras $(n=1)$. On average, respondents were 43 years of age, and began engaging in agricultural labor at nine years of age, on average (range 5-18 years).

Over participants' lifetimes, 16 (39\%) reported mixing agrichemicals, 14 (34\%) reported applying insecticide(s),
$20(49 \%)$ reported applying herbicide(s), $6(15 \%)$ reported applying fungicide(s), and $35(85 \%)$ reported applying fertilizer(s) (Table 2). The majority (93\%) reported being exposed to ambient spraying. PPE use occurred in less than $50 \%$ of the cases for each agrichemical use measure, with less PPE use ( $<3 \%$ total) being reported prior to first migration experience. Thirty-five participants $(85 \%)$ reported perceiving that agrichemical use affected their body in some way (Table 2 ).

\section{Social Sequence Analysis}

In the balanced panel data, $85 \%$ of participants who reported using herbicides on subsistence farms/milpas prior to
Table 1 Characteristics of study participants, $n=41$

\begin{tabular}{llll}
\hline Characteristic & $\begin{array}{l}\text { Total } \\
(\mathrm{n}=41)\end{array}$ & $\begin{array}{l}\text { Males } \\
(\mathrm{n}=14)\end{array}$ & $\begin{array}{l}\text { Females } \\
(\mathrm{n}=27)\end{array}$ \\
\hline $\begin{array}{l}\text { Languages spoken } \\
\text { Bilingual (Indigenous language }+ \text { Spanish), } \\
\quad n(\%)\end{array}$ & $16(39.0 \%)$ & $2(14.3 \%)$ & $13(48.2 \%)$ \\
$\quad \begin{array}{l}\text { Monolingual Spanish speakers, } n(\%) \\
\text { Age, } \text { mean }(S D)\end{array}$ & $25(61.0 \%)$ & $12(85.7 \%)$ & $14(51.9 \%)$ \\
Country of origin & $43.4(13.7)$ & $49.5(16.3)$ & $40.3(11.3)$ \\
$\quad \begin{array}{l}\text { Mexico, } n(\%) \\
\text { Guatemala, } n(\%)\end{array}$ & $22(53.7 \%)$ & $8(57.1 \%)$ & $14(51.9 \%)$ \\
Honduras, $n(\%)$ & $18(43.9 \%)$ & $5(35.7 \%)$ & $13(48.2 \%)$ \\
\hline
\end{tabular}

$S D$ standard deviation

${ }^{a}$ Languages spoken by participants included Mam, Nahuatl, Zapotec, Mixteco, Otomi, and Chinanteco

Table 2 Lifetime agrichemical use reported via LHC in an unbalanced panel of foreign born Latinx agricultural workers living in South Florida, $\mathrm{n}=1846$ person-years for 41 individuals

\begin{tabular}{|c|c|c|c|c|c|c|c|c|c|}
\hline \multirow[t]{2}{*}{ Agrichemical use reported via LHC } & \multicolumn{3}{|c|}{$\begin{array}{l}\text { Cumulative years experienced } \\
\text { event in host country }\end{array}$} & \multicolumn{3}{|c|}{$\begin{array}{l}\text { Cumulative years experienced } \\
\text { event following first migration }\end{array}$} & \multicolumn{3}{|c|}{$\begin{array}{l}\text { Cumulative years experienced } \\
\text { event in lifetime }\end{array}$} \\
\hline & $\mathrm{N}$ & $\%$ total & (mean, SD) & $\mathrm{N}$ & $\%$ total & (mean, SD) & $\mathrm{N}$ & $\%$ total & (mean, SD) \\
\hline Insecticide & 12 & $29 \%$ & $12.4(9.4)$ & 6 & $15 \%$ & $5.0(5.3)$ & 14 & $34 \%$ & $12.8(9.2)$ \\
\hline Used PPE & 0 & $0 \%$ & $0.0(0.0)$ & 3 & $7 \%$ & $7.7(6.4)$ & 3 & $7 \%$ & $7.7(6.4)$ \\
\hline Herbicide & 14 & $34 \%$ & $13.1(9.0)$ & 9 & $22 \%$ & $6.2(4.8)$ & 20 & $49 \%$ & $12(8.8)$ \\
\hline Used PPE & 0 & $0 \%$ & $0.0(0.0)$ & 5 & $12 \%$ & $6.4(5.2)$ & 5 & $12 \%$ & $6.4(5.2)$ \\
\hline Fungicide & 3 & $7 \%$ & $12.7(3.2)$ & 4 & $10 \%$ & $3.8(1.7)$ & 6 & $15 \%$ & $8.8(7.3)$ \\
\hline Used PPE & 0 & $0 \%$ & $0.0(0.0)$ & 3 & $7 \%$ & $4.0(1.0)$ & 3 & $7 \%$ & $4.0(1.0)$ \\
\hline Unknown chemical & 5 & $12 \%$ & $1.0(0.0)$ & 11 & $27 \%$ & $13.7(13.1)$ & 11 & $27 \%$ & $14.2(13.3)$ \\
\hline Used PPE & 1 & $2 \%$ & $1.0(0.0)$ & 2 & $5 \%$ & $11.5(12.0)$ & 2 & $5 \%$ & $12.0(12.7)$ \\
\hline Ambient spraying & 29 & $71 \%$ & $7.4(0.0)$ & 37 & $90 \%$ & $14.5(10.9)$ & 38 & $93 \%$ & $19.8(11.3)$ \\
\hline Used PPE & 0 & $0 \%$ & $0.0(0.0)$ & 0 & $0 \%$ & $0.0(0.0)$ & 0 & $0 \%$ & $0.0(0.0)$ \\
\hline Mixed chemical & 10 & $24 \%$ & $12.9(9.9)$ & 11 & $27 \%$ & $6.1(6.8)$ & 16 & $39 \%$ & $12.3(13.7)$ \\
\hline Used PPE & 0 & $0 \%$ & $0.0(0.0)$ & 4 & $10 \%$ & $10.3(8.8)$ & 4 & $10 \%$ & $9.3(5.8)$ \\
\hline Fertilizer & 30 & $73 \%$ & $11.3(7.5)$ & 16 & $39 \%$ & $10.8(11.8)$ & 35 & $85 \%$ & $14.6(11.6)$ \\
\hline Perceived chemicals affecting body & 24 & $59 \%$ & $8.2(6.4)$ & 32 & $78 \%$ & $13.7(11.5)$ & 35 & $85 \%$ & $18.1(11.8)$ \\
\hline
\end{tabular}

$L H C$ life history calendar, $S D$ standard deviation, $P P E$ personal protective equipment 
migrating to the US were able to articulate the names of the herbicides used in Central America or Mexico (Paraquat and Glyphosate were the most common), however none of the participants knew the names of herbicides used in the US. A similar pattern was observed for insecticides being articulated in Central America or Mexico (cypermethrin and parathion ("folidol") were the most common). The most common fertilizers used on milpas in Central America or Mexico were nitrogen/phosphorous/potassium combinations, ammonium sulphate, and urea. In completing the LHCs, several participants were reticent to describe ever having been exposed to agrichemicals during their work as undocumented migrants in the US for fear of retaliation by employers and had to be reminded of the confidentiality precautions taken by the research team.
PSTM values showed probabilities of 0.10 for subsistence farming with agrichemicals and 0.08 without agrichemicals prior to migration (Table 3 ). The probability of engaging in agricultural wage labor with agrichemical exposures was 0.68 in the year following first migration (Table 3). Exposure to ambient spraying comprised a majority of these exposures. Following the OM, a Calinski and Harabasz Index Pseudo-F of $0.16,1.04$, and 0.79 for two, three, and four cluster solutions was produced. The three-cluster solution presented in Fig. 1 was selected to classify sequences as:

1. Low exposure (Overall limited lifetime agrichemical use);

2. Moderate exposure (Limited subsistence farming with agrichemicals prior to migration, and more exposure
Table 3 Probability state transition values for occupationby-agrichemical categories relative to first migration in a balanced panel of foreign born Latinx agricultural workers living in South Florida, $\mathrm{n}=861$ person-years for 41 individuals
Fig. 1 Occupation-byagrichemical exposure sequence classes relative to experience of first migration to the United States in a sample of foreign born Latinx agricultural workers living in South Florida, $\mathrm{n}=41$

\begin{tabular}{llll}
\hline $\begin{array}{l}\text { Occupation-by-agrichemical categories used in } \\
\text { sequence analysis }\end{array}$ & $\begin{array}{l}\text { Total number of } \\
\text { person-years }\end{array}$ & $\begin{array}{l}\text { Probability migra- } \\
\text { tion follows event }\end{array}$ & $\begin{array}{l}\text { Probability event } \\
\text { follows migration }\end{array}$ \\
\hline Subsistence farming with agrichemicals & 219 & 0.10 & 0.00 \\
Subsistence farming without agrichemicals & 53 & 0.08 & 0.00 \\
Agricultural wage labor with agrichemicals & 286 & 0.00 & 0.68 \\
Agricultural wage labor without agrichemicals & 80 & 0.03 & 0.17 \\
Landscaping without agrichemicals & 14 & 0.00 & 0.02 \\
Landscaping with agrichemicals & 0 & 0.00 & 0.00 \\
Construction & 18 & 0.00 & 0.00 \\
Painting & 5 & 0.20 & 0.00 \\
Other work & 70 & 0.12 & 0.05 \\
Not working & 75 & 0.04 & 0.07 \\
\hline
\end{tabular}

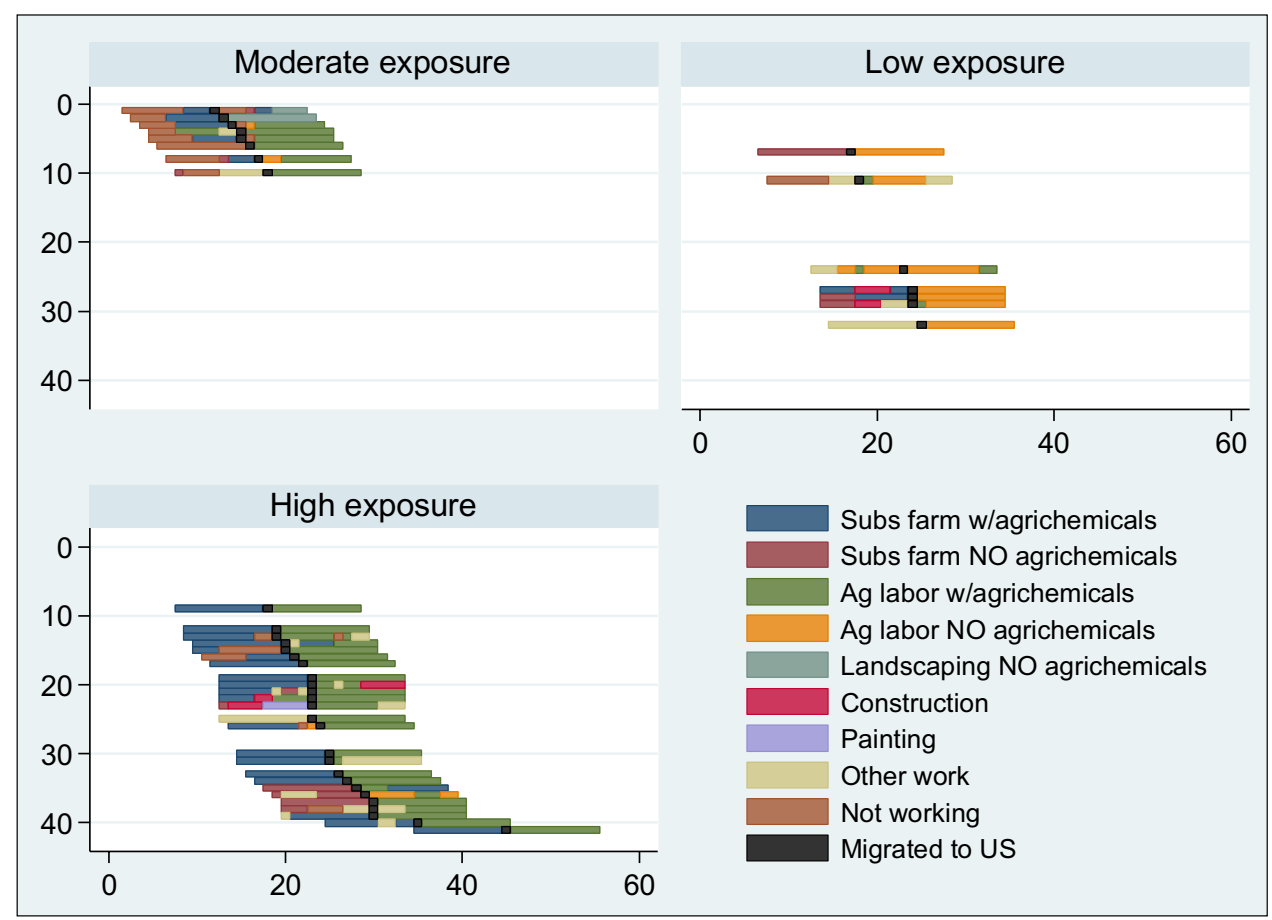


to agrichemicals in agricultural wage labor following migration to the US); and

3. High exposure (Long agrichemical exposures prior to and following migration).

\section{Random Intercept Models}

Overall, sequence class by TRM interactions were detected for any self-reported perceptions of agrichemical effects on the body, perceived effects on the eyes, and perceived effects on the CNS (Table 4). Effects for skin/nails were not evident (not shown). PLRC models illustrated that the odds of any perceived effects of agrichemicals on the body increased with time prior to migration in the moderate and high exposure sequence clusters and continued to increase $20 \%$ with each year following migration in the moderate exposure cluster (aOR 1.2, 95\% CI 1.0-1.4, p=0.07) (Table 4).

\section{Discussion}

In this study of 41 foreign born Latinx agricultural workers in South Florida, a LHC was piloted to characterize lifetime agrichemical exposures relative to international migration. The LHC was useful in identifying types of exposure trajectories relative to migration within Latinx agricultural workers. Findings have several implications for understanding how toxic exposures to agrichemicals are perceived and self-reported by Latinx agricultural workers who emigrated from Mexico and Central America.

First, the lifetime exposure clusters identified in the present study combined with workers' ability to articulate agrichemicals used on subsistence farms in Mexico or Central America prior to migrating (particularly herbicides and insecticides), suggests that ability to recall lifetime exposures may vary within Latinx agricultural workers in the US who worked subsistence farms in their home countries. The documentation of Paraquat use on subsistence farms in Mexico/Central America is of particular interest, as Paraquat is considered to be one of the most acute toxic herbicides [44]. Paraquat may cause fatal poisonings by dermal absorption of diluted paraquat, ingestion of even small amounts, and possibly by inhalation [45, 46], and acute intoxication has been associated with acute kidney injury in humans [47, 48]. Furthermore, PLRC models in the present study illustrated that the odds of perceived effects of agrichemicals on the airways increased with time prior to migration in high exposure sequence clusters. This is notable, as Paraquat accumulates in the lung after the ingestion of small quantities [49]. The finding may also reflect a lack of PPE while working close contact with a range of agrichemicals in Central America/Mexico. Further research concerning recall of early-life, pre-international migration exposures on subsistence farms could help elucidate potential chronic agrichemical exposures among agricultural workers currently working in the US.

Table 4 The relationship between occupation-by-agrichemical sequence clusters and self-reported perceptions of agrichemical effects on the body in a balanced panel of foreign born Latinx agricultural workers living in South Florida, $n=861$ person-years for 41 individuals

\begin{tabular}{|c|c|c|c|c|c|c|c|c|c|}
\hline \multirow[b]{2}{*}{ Characteristic } & & \multicolumn{2}{|l|}{ Any } & \multicolumn{2}{|l|}{ Eyes } & \multicolumn{2}{|l|}{ CNS } & \multicolumn{2}{|c|}{ Airways } \\
\hline & & $\mathrm{aOR}$ & $95 \% \mathrm{CI}$ & $\mathrm{aOR}$ & $95 \% \mathrm{CI}$ & $\mathrm{aOR}$ & $95 \% \mathrm{CI}$ & $\mathrm{aOR}$ & $95 \% \mathrm{CI}$ \\
\hline \multicolumn{10}{|c|}{ Random intercept models with TRM $\times$ sequence cluster interactions, $n=861$} \\
\hline \multicolumn{2}{|l|}{ Gender $^{\mathrm{a}}$} & 0.8 & $0.1-6.6$ & 0.7 & $0.0-14.9$ & 12.0 & $0.8-185.2$ & 1.7 & $0.2-16.4$ \\
\hline \multicolumn{2}{|l|}{ Language $^{\mathrm{b}}$} & 4.8 & $0.6-35.3$ & 1.6 & $0.1-33.4$ & 17.3 & $1.2-245.4$ & 1.1 & $0.1-10.6$ \\
\hline \multicolumn{2}{|l|}{$\mathrm{TRM} \times$ cluster interaction $^{\mathrm{c}}$} & Yes & & Yes & & Yes & & & \\
\hline \multicolumn{10}{|c|}{ Piecewise-linear random-coefficient models } \\
\hline \multirow[t]{2}{*}{ Low exposure cluster, $n=147^{\mathrm{d}}$} & TPM & 1.0 & $1.0-1.0$ & 1.0 & $1.0-1.0$ & 1.0 & $1.0-1.0$ & 1.0 & $1.0-1.0$ \\
\hline & TFM & 1.2 & $0.9-1.6$ & 1.0 & $0.7-1.4$ & 1.0 & $0.7-1.4$ & 1.0 & $0.7-1.4$ \\
\hline \multirow[t]{2}{*}{ Moderate exposure cluster, $n=168^{\mathrm{d}}$} & TPM & 1.6 & $1.2-2.1$ & 1.0 & $1.0-1.0$ & 3.2 & $1.1-9.3$ & 2.6 & $1.0-6.4$ \\
\hline & TFM & 1.2 & $1.0-1.4$ & 25.5 & $0.9-749.1$ & 1.1 & $0.9-1.4$ & 0.9 & $0.7-1.1$ \\
\hline \multirow[t]{2}{*}{ High exposure cluster, $\mathrm{n}=525^{\mathrm{d}}$} & TPM & 1.1 & $1.0-1.3$ & 1.2 & $1.1-1.3$ & 1.2 & $1.0-1.3$ & 1.4 & $1.2-1.5$ \\
\hline & TFM & 1.0 & $0.9-1.1$ & 1.0 & $0.9-1.1$ & 1.0 & $0.9-1.1$ & 1.0 & $0.9-1.1$ \\
\hline
\end{tabular}

aOR adjusted odds ratio, $C I$ confidence interval, TRM time relative to migration, TPM time prior to migration, TFM time following migration, CNS Central Nervous System

${ }^{a}$ Estimates are for males, females are the reference group

${ }^{\mathrm{b}}$ Estimates are for indigenous language speakers, monolingual Spanish speakers are the reference group

${ }^{\mathrm{c}}$ Refers to whether TRM x sequence cluster interactions were statistically significant in random intercept models including all clusters, gender, and language in a sample with 861 observations

${ }^{\mathrm{d}}$ Estimates are derived from a piecewise-linear random-coefficient model, controlling for gender and language 
Second, sequence analyses revealed differences in trajectories of self-reported exposure among foreign-born Latinx agricultural workers relative to international migration, which was related to the ways in which workers perceived effects of agrichemicals on the body. Participants with high lifetime exposures reported more overall effects on the body in the time period preceding migration, and the moderate lifetime exposure class reported more overall effects in the time period following migration. In both classes, the most common post-migration agrichemical exposure was ambient spraying (not mixing or applicator tasks). These findings compliment one study of Latinx farmworkers and workers with no occupational pesticide exposure, but where elevated likelihoods of cholinesterase depression were found during the agricultural season, illustrating that exposure occurred despite workers' classifications as unexposed workers [50]. However, the present study's finding of differential effects relative to exposure class and international migration experience may reflect worker "acclimation" to the harmful effects of agrichemicals over time in the high exposure group, and go unreported.

It is noteworthy that workers with high lifetime agrichemical exposures prior to migrating were less likely to report an increased perceived effect on the body following migration despite continued exposure. These findings compliment a focus group study that found farmworkers relying on their senses to detect the presence of pesticides, and believing that individuals are affected differently by pesticides [8]. Indeed, early-life exposures prior to international migration, and perceptions of the health effects of those exposures, may result in perceptions of "acclimation" among some agricultural workers who normalize and do not complain about exposures. Our finding that some workers were reticent to even report agrichemical exposures in as a result of fear of retaliation by US employers reflects structural violence that manifests in workers bodies (many of whom are undocumented), and which is buttressed by recurrent pressures in US agricultural wage labor to not complain as a replaceable, undocumented worker [51]. Furthermore, disparities in access to healthcare for workers in Florida are similar for Latinx agricultural workers elsewhere in the US. In Florida, one ethnographic study documented crew leaders navigating Latinx agricultural workers to doctors designated by companies, high emergency room use, and workers returning to Mexico for treatments [52]. In another study of middle-aged and elderly farm workers near the US border, the majority reported persistent musculoskeletal injury pain, but fewer than $25 \%$ of injured participants reported receiving any form of conventional medical treatment [53]. Given the systematic inequalities that undocumented, foreign born workers face in navigating work and seeking healthcare, it is possible that those who have suffered the most exposures over the lifetime are less likely to self-report it once inside the US.

\section{Limitations}

Results are based on only 41 foreign born Latinx agricultural workers and cannot be generalized to workers in other environments. The small sample size limited the ability to test for sequence cluster interaction effects for the PLRC models in the balanced panel data, and a greater number of LHC participants would allow for such tests to be conducted in the future. Significant data loss occurred to balance the panel data, which could be reduced in future studies by altering eligibility criteria relative to time of migration. More women were included in the study as opposed to men, which likely reflected bias in the recruitment patterns. An attempt was made to adjust for the gender imbalance, but it persisted throughout data collection. Finally, unobserved dynamics between LHC administrators and LHC participants may produce unobserved biases in the data. Using a semistructured interview instrument to facilitate LHC completion was intended to reduce such biases, but they nonetheless remain underexplored in research using LHCs.

\section{Conclusion}

In this pilot study of 41 foreign born Latinx agricultural workers in South Florida, three classes of occupation-byagrichemical exposure sequences were detected in the sample, which corresponded to participants' self-reported perceptions of agrichemical effects on the body relative to international migration. The results suggest the presence of differential lifetime agrichemical exposure trajectories relative to international migration in Latinx agricultural workers, and invite further research regarding lifetime exposure measurement in foreign born workers. Future research exploring LHC validity in foreign born Latinx agricultural workers is warranted.

Acknowledgements We would like to thank Maria Carmona, Adolfho Romero, and the Farmworker Association of Florida for their support in conducting this study. This research was supported in part by the National Institute on Minority Health and Health Disparities of the National Institutes of Health Under Award Number NIMHD (U54MD012393), Florida International University Research Center in Minority Institutions. The content is solely the responsibility of the authors and does not necessarily represent the official views of the National Institutes of Health.

\section{References}

1. ILO code of practice. Safety and health in agriculture. Geneva: International Labour Office - ILO; 2011.

2. Arcury TA, Quandt SA. Pesticide exposure among farmworkers and their families in the eastern United States: matters of social 
and environmental justice. In: Arcury TA, Quandt SA, editors. Latino farmworkers in the eastern United States: health, safety, and justice. New York: Springer; 2009. p. 103-29.

3. Nguyen TH, Bertin M, Bodin J, Fouquet N, Bonvallot N, Roquelaure Y. Multiple exposures and coexposures to occupational hazards among agricultural workers: a systematic review of observational studies. Saf Health Work. 2018;9(3):239-48.

4. Boedeker W, Watts M, Clausing P, Marquez E. The global distribution of acute unintentional pesticide poisoning: estimations based on a systematic review. BMC Public Health. 2020;20:1875.

5. Arcury TA, Quandt SA. Pesticides at work and at home: exposure of migrant farmworkers. Lancet. 2003;362:9400.

6. Arcury TA, Nguyen HT, Summers P, Talton JW, Holbrook LC, Walker FO, Chen H, Howard TD, Galván L, Quandt SA. Lifetime and current pesticide exposure among Latino farmworkers in comparison to other Latino immigrants. Am J Ind Med. 2014;57(7):776-87.

7. Srivastava AK, Kesavachann C. Health effects of pesticides. Boca Raton: CRC Press, Taylor \& Francis Group; 2019.

8. Flocks J, Monaghan P, Albrecht S, Bahena A. Florida farmworkers' perceptions and lay knowledge of occupational pesticides. J Community Health. 2007;32(3):181-94.

9. Anastario M, Arias Rodas MG, Escobar Arteaga MA, Villanueva C, Chacón Serrano F, Ferdowsian H. Genitourinary systems entangled with shifting environments in a Salvadoran subsistence farming community. Med Anthropol Q. 2020;35:246.

10. Borlaug NE, Narvaez I, Aresvik O, Anderson RG. A green revolution yields a golden harvest. Columbia J World Bus. 1969;4:9-19.

11. Nazarea V. Cultural memory and biodiversity. Tuscon: The University of Arizona Press; 1998.

12. Ford A, Nigh R. The Maya forest garden: eight millenia of sustainable cultivation of the tropical woodlands. Walnut Creek: Left Coast Press, Inc.; 2015.

13. Boege E. El patrimonio biocultural de los pueblos indigenas de Mexico. Mexico: Instituto Nacional de Antropologia e Historia, Comision Nacional para el Desarrollo de los Pueblos Indígenas; 2008.

14. Jansen K. Political ecology, mountain agriculture, and knowledge in Honduras. Amsterdam: Thela Publishers; 1998.

15. Demographic and Mortality Trends in the Region of the Americas, 1980-2000. Epidemiological Bulletin/ Pan American Health Organization 2002; 233.

16. Brooks DR, Ramirez-Rubio O, Amador JJ. CKD in Central America: a hot issue. Am J Kidney Dis. 2012;59(4):481-4.

17. Herrera-Valdés R, Orantes-Navarro CM, Almaguer-López M, et al. Clinical characteristics of chronic kidney disease of nontraditional causes in Salvadoran farming communities. MEDICC Rev. 2014;16:39-48.

18. Orantes-Navarro CM, Herrera-Valdés R, Almaguer-Lopez M, et al. Epidemiology of chronic kidney disease in adults of Salvadoran agricultural communities. MEDICC Rev. 2014;16:23-30.

19. Orantes-Navarro CM, Herrera-Valdés R, Almaguer-Lopez M, et al. Epidemiological characteristics of chronic kidney disease of non-traditional causes in women of agricultural communities of El Salvador. Clin Nephrol. 2015;83(1):24-31.

20. Martín-Cleary C, Ortiz A. CKD hotspots around the world: where, why and what the lessons are. Clin Kidney J. 2014;7:519-23.

21. Mendley SR, Levin A, Correa-Rotter R, et al. Chronic kidney diseases in agricultural communities: report from a workshop. Kidney Int. 2019;96:1071-6.

22. Johnson RJ, Wesseling C, Newman LS. Chronic kidney disease of unknown cause in agricultural communities. N Engl J Med. 2019;380:1843-52.

23. Peraza S, Wesseling C, Aragon A, et al. Decreased kidney function among agricultural workers in El Salvador. Am J Kidney Dis. 2012;59(4):531-40.
24 Mix J, Elon L, Vi Thien Mac V, et al. Hydration status, kidney function, and kidney injury in Florida agricultural workers. J Occup Environ Med. 2018;60(5):e253-60.

25. Gallo-Ruiz L, Sennett CM, Sánchez-Delgado M, et al. Prevalence and risk factors for CKD among brickmaking workers in La Paz Centro, Nicaragua. Am J Kidney Dis. 2019;74(2):239-47.

26. Roncal-Jiménez C, Lanaspa MA, Jensen T, Sanchez-Lozada LG, Johnson RJ. Mechanisms by which dehydration may lead to chronic kidney disease. Ann Nutr Metab. 2015;66(Suppl 3):10-3.

27. Athuraliya NTC, Abeysekera TDJ, Amerasinghe PH, et al. Uncertain Etiologies of proteinuric-chronic kidney disease in rural Sri Lanka. Kidney Int. 2011;80(11):1212-21.

28. Cornwell B. Social sequence analysis: methods and applications. New York: Cambridge University Press; 2015.

29. Simmel G. Conflict and the web of group affiliations. Gelncoe: Free Press; 1955.

30. U.S. Census Bureau. QuickFacts: Immokalee CDP, Florida. https://www.census.gov/quickfacts/fact/table/immokaleecdpflo rida/POP010210. 2010.

31. Freedman D, Thornton A, Camburn D, Alwin D, Young-DeMarco L. The life history calendar: a technique for collecting retrospective data. Sociol Methodol. 1988;18:37-68.

32. Monge P, Wesseling C, Guardado J, Lundberg I, Ahlbom A, Cantor KP, Weiderpass E, Partanen T. Parental occupational exposure to pesticides and the risk of childhood leukemia in Costa Rica. Scand J Work Environ Health. 2007;1:293-303.

33. Zahm SH, Colt JS, Engel LS, Keifer MC, Alvarado AJ, Burau K, Butterfield P, Caldera S, Cooper SP, Garcia D, Hanis C. Development of a life events/icon calendar questionnaire to ascertain occupational histories and other characteristics of migrant farmworkers. Am J Ind Med. 2001;40(5):490-501.

34. Rodríguez T, de Joode BV, Lindh CH, Rojas M, Lundberg I, Wesseling C. Assessment of long-term and recent pesticide exposure among rural school children in Nicaragua. Occup Environ Med. 2012;69(2):119-25.

35. Quandt SA, Mora DC, Seering TL, Chen H, Arcury TA, Laurienti PJ. Using life history calendars to estimate in utero and early life pesticide exposure of Latinx children in farmworker families. Int J Environ Res Public Health. 2020;17(10):3478.

36. Hoppin JA, Guzman JD, Tolbert PE, Flagg EW. Agricultural exposure history among African-American farmers in Georgia. J Toxicol Environ Health A. 2001;63(4):237-41.

37. Hoppin JA, Tolbert PE, Flagg EW, Blair A, Zahm SH. Use of a life events calendar approach to elicit occupational history from farmers. Am J Ind Med. 1998;34(5):470-6.

38. Glasner T, Van der Vaart W. Applications of calendar instruments in social surveys: a review. Qual Quant. 2009;43(3):333-49.

39. Engel LS, Keifer MC, Thompson ML, Zahm SH. Test-retest reliability of an icon/calendar-based questionnaire used to assess occupational history. Am J Ind Med. 2001;40(5):512-22.

40. Butler-Dawson J, Galvin K, Thorne PS, Rohlman DS. Organophosphorus pesticide residue levels in homes located near orchards. J Occup Environ Hyg. 2018;15(12):847-56.

41. Engel LS, Keifer MC, Zahm SH. Comparison of a traditional questionnaire with an icon/calendar-based questionnaire to assess occupational history. Am J Ind Med. 2001;40(5):502-11.

42. Abbott A, Tsay A. Sequence analysis and optimal matching methods in sociology: review and prospect. Sociol Methods Res. 2000;29(1):3-33.

43. Brzinsky-Fay C, Kohler U, Luniak M. Sequence analysis with Stata. Stand Genomic Sci. 2006;6(4):435-60.

44. Yanling W, Duo G, Zuojun G, et al. Radiomics nomogram analyses for differentiating pneumonia and acute paraquat lung injury. Sci Rep. 2019;9:15029. 
45 Wesseling C, Hogstedt C, Picado A. Unintentional fatal paraquat poisonings among agricultural workers in Costa Rica: report of 15 cases. Am J Ind Med. 1997;32(5):433-41.

46 Soloukides A, Moutzouris D-A, Kassimatis T, Metaxatos G, Hadjiconstantinou V. A fatal cause of paraquat poisoning following minimal dermal exposure. Ren Fail. 2007;29:375.

47. Kim S-J, Gil H-W, Yang J-O, Lee E-Y, Hong S-Y. The clinical features of acute kidney injury in patients with acute paraquat intoxication. Nephrol Dial Tansplant. 2009;24:1126-32.

48. McClean M, Laws R, Ramirez Rubio O, Brooks D. Industrial hygiene/occupational health assessment: Evaluating potential hazards associated with chemicals and work practices at the Ingenio San Antonio (Chichigalpa, Nicaragua). Boston University School of Public Health. 2010. http://www.cao-ombudsman.org/docum ents/FINALIHReport-AUG302010-ENGLISH.pdf. Accessed 13 Aug 132021.

49 Lock EA, Wilks MF. Paraquat. In: Hayes WJ, Laws ER, editors. Handbook of pesticide toxicology. 2nd ed. San Diego: Academic Press; 2001.

50 Quandt SA, Pope CN, Chen H, Summers P, Arcury TA. Longitudinal assessment of blood cholinesterase activities over 2 consecutive years among latino nonfarmworkers and pesticideexposed farmworkers in North Carolina. J Occup Environ Med. 2015;57(8):851-7.

51. Holmes SM. Fresh fruit, broken bodies. Berkeley: University of California Press; 2013.

52. Tovar-Aguilar JA. Strategies of safety and health among citrus farmworkers in Florida: a cultural and social network approach (dissertation). Gainseville: University of Florida; 2014.

53. Weigel MM, Armijos RX, Beltran O. Musculoskeletal injury, functional disability, and health-related quality of life in aging Mexican immigrant farmworkers. J Immigr Minor Health. 2014;16(5):904-13.

Publisher's Note Springer Nature remains neutral with regard to jurisdictional claims in published maps and institutional affiliations. 